\title{
Perejivânie: uma aproximação ao estado da arte das pesquisas
}

\author{
Perezhivanie: an approach to the state-of-the-art of research
}

\author{
Letícia Raboud Mascarenhas de Andrade ${ }^{1}$
}

Herculano Ricardo Campos ${ }^{2}$

\section{RESUMO}

O conceito de perejivânie (vivência), articulado à teoria histórico-cultural, referese à unidade sistêmica da vida consciente, compreendendo a integralidade entre afeto e cognição e a relação dialética entre o indivíduo e seu meio no estudo do desenvolvimento humano. Trata-se de um conceito importante para a perspectiva histórico-cultural que aparece tardiamente e de forma inacabada na obra de Vigotski. É ainda um conceito de apropriação recente por autores ocidentais cuja referência nos trabalhos científicos vem crescendo e se desdobrando em diferentes contextos. O presente trabalho se propõe a fazer uma categorização quantitativa da produção envolvendo o conceito de vivência, bem como apontar aspectos a serem analisados. O levantamento das produções foi feito através do portal de periódicos da CAPES, abarcando trabalhos publicados até 2018 , em português, espanhol e inglês. Como descritores utilizaram-se distintas nomenclaturas do nome russo: perezhivanie, perezhivaniya, perejivanie, e ainda combinações como "vivência" e "Vigotski", dentre outros. Foram categorizados 122 trabalhos que trataram do conceito em foco por: ano de publicação, autor, local de produção (instituição, país), periódico de emissão e abordagem do conceito (enquanto objeto de discussão, unidade de análise ou elemento teórico central). Os resultados indicaram crescimento exponencial da produção no recorte estudado, disseminação dos trabalhos por 22 países, além de protagonismo da Austrália e Brasil

ABSTRACT

The concept of perezhivanie, associated with the historical-cultural theory, refers to a systemic unit of consciousness, comprehending the integrity of relation between affect and cognition, and the dialectical relation between individual and environment in the study of human development. It is an important concept to historical-cultural perspective which appears late and is unfinished in Vygotsky's work. It is also a concept of recent apprehension by western authors whose reference in scientific works is growing and unfolding in different contexts. The present study intends to make a quantitative categorization of the scientific production involving the concept of perezhivanie, as well as indicate aspects to be analyzed. The search for scientific production was made through the journals portal of CAPES, involving works published untill 2018, in Portuguese, Spanish and English. As descriptors distincts nomenclatures of the russian name were used: perezhivanie, perezhivaniya, perejivanie, as well as combinations like "vivência" and "Vigotski». The quantity of 122 scientific works that dealt with perezhivanie were categorized by: year of publication, author, place of production (institution, country), journal and concept approach (as an object of discussion, unit of analysis and central theoretical aspect). The results indicated an exponential growth of production in the excerpt analyzed, along with diffusion in 22 countries and protagonism of Australia and Brazil in the world scene. Expansion and deepening possibilities of the
\end{abstract}

\footnotetext{
${ }_{1}^{1}$ Doutoranda pelo Programa de Pós-graduação em Psicologia da Universidade Federal do Rio Grande do Norte, campus Natal, Brasil. E-mail: lelermandrade@gmail.com.

2 Professor Titular do Departamento de Psicologia e do Programa de Pós-graduação em Psicologia da UFRN, Brasil. E-mail: herculanorcampos@gmail.com.
} 
no cenário mundial. Apontam-se ainda possibilidades de ampliação e aprofundamento do atual estudo, tendo em vista chegar a um panorama mais completo das produções, além de explorar formas de entendimento do conceito e campos de utilização deste. current study were also indicated in view of a thorough picture of the productions, likewise exploring the concept's perspectives and fields of use.
Palavras-chave: Pesquisa bibliográfica. Perejivânie. Psicologia histórico-cultural.
Keywords: Bibliographical research. Perezhivanie. Historical-cultural psychology (CHAT)

\section{Introdução}

O conceito de vivência (perejivânie), presente nas articulações teóricas da obra de Vigotski, tem sido alvo de interesse e estudo crescentes nos últimos anos por pesquisadores de todo o mundo. Veresov (2014) declara que há consenso quanto à sua relevância na perspectiva histórico-cultural e considera o conceito como um dos menos explorados pela literatura contemporânea dedicada a Vigotski, embora esse cenário esteja em curso de mudança. Nessa direção, o periódico Mind, Culture and Activity, associado à International Society of Cultural-Historical Activity Research (ISCAR, sociedade internacional voltada para a pesquisa na perspectiva histórico-cultural), elaborou e publicou, em 2016, o dossiê Symposium on Perezhivanie. Nele, Cole e Gajdamschko (2016) explicam em nota a necessidade de discussão do tema percebida após recebimento, pelo periódico, de meia dúzia de artigos tratando de alguma forma do conceito em foco e revelando pouca concordância entre os autores quanto à sua tradução para o inglês. As dificuldades mencionadas envolvem questões linguísticas e culturais, não existindo equivalente satisfatório para o termo russo, sobretudo no inglês, bem como questões conceituais que serão exploradas nos parágrafos seguintes.

Perejivânie é um termo usado no cotidiano e no contexto da literatura e cultura russa, assumindo na obra de Vigotski, em diferentes momentos, sentidos específicos, distintos dos de origem, ainda que com eles relacionados. Toassa e Souza (2010) expõem uma análise etimológica e traduções possíveis do vocábulo, apresentando a explicação da tradutora Teresa Prout sobre o termo servir para expressar a ideia de que uma situação objetiva pode ser interpretada, percebida, experimentada ou vivida de forma diferente por diversos sujeitos, sendo a 
expressão "experiência emocional" - de cunho marcadamente afetivo -, e "interpretação" - de cunho racional -, traduções pouco adequadas. O termo integraria diversos aspectos da vida psíquica, aspectos afetivos como cognitivos. Toassa e Souza (2010) recorrem ainda ao linguista Bóris Schnaiderman para analisar a palavra em foco. Deste trabalho sobressai a relação do vocábulo com o verbo viver (abarcando condições particulares de vida) e a ideia de sofrer algo, atravessar uma situação difícil de vida, denotando ainda uma ação inacabada, em fluxo. Para o português e o espanhol, vivência é a tradução mais adequada de perejivânie, tendo em vista sua etimologia relacionada ao viver.

Conforme trazido por Toassa e Souza (2010), o termo perejivânie perpassa a obra de Vigotski apresentando diferentes significados e constituindo história própria. Veresov e Fleer (2016) trazem uma definição feita por Vigotski, de 1931, conforme consta no Psychological Dictionary (produzido em parceria com Varshava), na qual o autor declara que todo processo psicológico é perejivânie. Essa definição genérica, no entanto, não se situa no contexto de articulação da teoria histórico-cultural, referindo-se ao significado tradicional do termo à época para a psicologia.

No livro Psicologia da arte, do início de seu percurso acadêmico, Vigotski traz outra compreensão de perejivânie (perejivânie estética), enfocando uma dimensão fenomenológica que se debruça sobre o processo de vivência (como) e o seu conteúdo (o quê) (VERESOV; FLEER, 2016). Da mesma forma, Toassa e Souza (2010) reiteram essa compreensão, neste primeiro Vigotski, de uma vivência (perejivânie) de caráter fenomenológico, marcada por sentimentos e sensações que deverão ser compreendidas depois de vivenciadas, e que abarcam relações mútuas sujeito-mundo.

É a partir dos anos 1930, em seus últimos anos de vida, que Vigotski apresentará perejivânie (vivência) como um conceito articulado à teoria históricocultural, ainda que este trabalho não tenha sido concluído ou aprofundado, tendo em vista a morte do autor em 1934. Roth e Jornet (2016) observam que esse movimento se relaciona ao desafio, colocado por Vigotski, de lidar com a questão psicofísica (mente e corpo) e com a superação da separação entre cognição e afeto, pensamento e linguagem. Vivência (perejivânie) é introduzida como conceito nas 
aulas de Vigotski sobre os fundamentos da pedologia. Trata-se, então, de um conceito (não uma noção ou definição) relacionado ao processo de desenvolvimento e, mais especificamente, ao papel do meio no desenvolvimento (VERESOV; FLEER, 2016). Nesse contexto, Vigotski (1935/2018) compreende vivência enquanto um prisma que refrata a influência do meio sobre o desenvolvimento da criança. A vivência é compreendida enquanto unidade que reúne características pessoais e do ambiente. Nas palavras do autor:

Vivência é uma unidade na qual se representa, de modo indivisível, por um lado, o meio, o que se vivencia - a vivência está sempre relacionada a algo que está fora da pessoa -, e, por outro lado, como eu vivencio isso. (VIGOTSKI, 2018, p. 78)

Tendo em vista a variedade de significados e contextos de uso da palavra perejivânie (vivência), além de questões de tradução, e o fato de vivência (perejivânie) enquanto conceito articulado à teoria histórico-cultural ser uma construção não acabada e pouco desenvolvida, devido à morte precoce do autor, é compreensível que falte clareza quanto à definição e utilização do termo nas produções que o compreendem. Essa abertura e imprecisão apresenta tanto potencialidades quanto desafios e perigos. Clarà (2016) enfatiza as "muitas vidas" da palavra perejivânie e como ela fomenta diferentes conceitos e perspectivas, sendo utilizada para distintos fins e relevante em diferentes interesses de pesquisa. Da mesma forma, como observado por Smagorinsky apud Veresov e Fleer (2016), há também o risco de a vivência revelar-se mais uma "noção hipnótica", superficial, do que um conceito com real significado.

Depois de contextualizar brevemente o conceito de vivência na obra de Vigotski, seus significados, possibilidades de interpretação, potencialidades e desafios, além de pontuar a atenção crescente de pesquisadores quanto à sua utilização, o presente trabalho se propõe a fazer um levantamento das produções envolvendo vivência, mais especificamente a vivência enquanto conceito articulado à teoria histórico-cultural. $\mathrm{O}$ objetivo é ter uma primeira aproximação quantitativa das produções, enfocando aspectos como: autores (universidade de origem, local de produção), ano de publicação, periódicos (quando se tratar de 
artigos), forma de abordagem do conceito nas produções, além de apontar aspectos a serem analisados. O crivo utilizado foram trabalhos publicados até o ano de 2018 disponíveis em inglês, português e espanhol.

\section{Aspectos metodológicos}

Conforme trazido no parágrafo anterior, foi realizado levantamento das produções envolvendo vivência enquanto conceito articulado à teoria históricocultural, contemplando os idiomas inglês, português e espanhol. A pesquisa foi feita através do portal de periódicos da CAPES (Coordenação de Aperfeiçoamento de Pessoal de Nível Superior), que possui ampla cobertura de acesso aos mais importantes periódicos e bases de dados tanto a nível nacional como internacional.

Utilizaram-se descritores tendo em vista as diferentes nomenclaturas do termo vivência que apareciam nas obras: perejivânie, perezhivaniya, pereghivanie e perezivanie, sendo que apenas as duas primeiras (além da mais comum em língua inglesa, perezhivanie) trouxeram resultados contemplando o conceito nos moldes procurados. Quando uma nomenclatura diferente era encontrada nas produções, esta era utilizada como descritor na busca por novos trabalhos. Também foram utilizados como descritores o termo "vivência" (sem o acento circunflexo, posto que deste modo é possível abarcá-lo nas duas situações, com e sem acento, tendo em vista a diferença de escrita para o português e o espanhol) associado a "Vigotski" (com caractere especial "*” nos dois "i”, visando a abranger suas distintas nomenclaturas: Vygotsky, Vygotski, Vigotsky, Vigotski). Foram testadas ainda outras combinações de descritores que obtiveram resultados referentes ao conceito buscado, embora pouco expressivos, tais como emotional experience, experiencing, social situation of development (e suas versões em português e espanhol) e "unidade afetivo cognitiva" (mais a versão em espanhol), todos associados a "Vigotski" (escrito com caracteres especiais). Os dois primeiros termos (emotional experience e experiencing) relacionam-se a traduções comuns para vivência na língua inglesa; social situation of development refere-se a um conceito intimamente ligado ao de vivência; e, por fim, "unidade afetivo cognitiva" pode ser uma forma breve e sucinta de referir-se à vivência. Também foi utilizado o descritor lived experience, tradução inglesa comum para vivência, no entanto 
não se obtiveram resultados pertinentes e que já não tivessem sido encontrados com o uso de outros termos. O único filtro utilizado nas pesquisas avançadas do portal de periódicos da CAPES foi a data final, para os trabalhos, equivalendo ao último dia de 2018.

A busca com o descritor perezhivanie, com a opção "expandir meus resultados", deu acesso a 26 páginas de resultados, o que significa aproximadamente 260 trabalhos (dez por página), contando com a ocasional repetição de títulos e artigos em línguas que não inglês, português ou espanhol. No caso da busca com este descritor, tendo em vista a abordagem direta do termo em foco, todos os trabalhos foram conferidos e triados. Outro descritor que obteve muitos resultados foi "vivência" associado a "Vigotski" (acima de 30 páginas). Nesta situação, apenas os trabalhos das dez primeiras páginas (100 trabalhos) foram conferidos e triados, pois observou-se que essa combinação de descritores produziu, em grande parte, resultados não pertinentes ao foco da pesquisa. Os resultados para emotional experience, experiencing e lived experience foram também muito numerosos (acima de 30 páginas, no primeiro caso; acima de 100 páginas, no segundo; por volta de 100 páginas, no terceiro). Como foi observada pouca pertinência dos resultados com o propósito da busca, apenas os títulos das cinco primeiras páginas (50 trabalhos) de cada combinação de descritores foram conferidos e triados. Os demais descritores não mencionados neste parágrafo obtiveram poucos resultados (abaixo de três páginas) e puderam ser todos verificados. No portal de periódicos da CAPES os resultados estão ordenados por relevância.

Também foi realizada busca por trabalhos em francês, utilizando como descritores os termos expérience vécue (experiência vivida) e expérience émotionnelle (experiência emocional), termos que à semelhança do inglês (experiencing e emotional experience) são traduções possíveis para vivência, associados a "Vigotski". No entanto, não se obteve resultados pertinentes à pesquisa.

Os trabalhos buscados passaram por uma triagem a partir, sobretudo, da leitura dos resumos. Um primeiro filtro foi feito para saber quais, dentre os textos, referiam-se de fato a vivência e, destes últimos, quais referiam-se à 
vivência enquanto conceito articulado à perspectiva histórico-cultural. Ao longo da leitura dos resumos foi percebida possibilidade de organização dos trabalhos pela forma de abordagem do conceito. Três categorias foram criadas: vivência enquanto objeto de discussão, unidade de análise e elemento teórico central.

Vivência enquanto objeto de discussão, como o nome diz, refere-se aos trabalhos cujo foco principal é a discussão do conceito ou de aspectos relacionados ao conceito em foco. Trata-se de trabalhos de caráter predominantemente teórico. Vivência como unidade de análise, também como o nome revela, refere-se a trabalhos que utilizam o conceito como unidade de análise, ou principal unidade de análise, na investigação de fenômenos. Trata-se, principalmente, de trabalhos empíricos e alguns teóricos que se debruçam sobre a utilização do conceito para a investigação de fenômenos. Por fim, vivência como elemento teórico central diz respeito aos trabalhos em que o conceito constitui o arcabouço teórico central, dialogando com outros conceitos, sem constituir foco de discussão ou unidade de análise central. Trata-se de trabalhos tanto teóricos, com discussão e articulação a conceitos de diferentes perspectivas, quanto empíricos, em que vivência constitui uma lente teórica complementar na observação dos fenômenos. Os trabalhos que apenas mencionavam o conceito de vivência, ou nos quais a referência era pouco expressiva e/ou periférica à discussão trazida, não foram considerados para análise.

Os artigos que atenderam aos critérios para a coleta foram tabulados contemplando as seguintes categorias: título, tipo de publicação (artigo, capítulo de livro, tese ou dissertação), autor, universidade de origem, ano de publicação, país de origem (ligado às universidades), periódicos em que foram publicados e modo de abordagem do conceito (objeto de discussão, unidade de análise ou elemento teórico central). Alguns trabalhos analisados, cerca de dez, não se apresentaram como fruto da pesquisa sistemática realizada e foram obtidos de outras formas, sobretudo de indicações e disponibilização por terceiros. Estes referem-se, principalmente, a capítulos de livros. 


\section{Resultados e discussão}

Dos materiais pesquisados não foi possível ter acesso a 74 títulos (referentes aos descritores perezhivanie, perezhivaniya e "vivência" + "Vigotski") para triagem. Dentre os trabalhos triados que abordaram vivência como conceito articulado à teoria histórico-cultural, 60 o fizeram de forma periférica ou pouco expressiva, enquanto 122 referiram-se ao conceito de modo expressivo.

Tabela 1 - Distribuição da produção quanto ao tipo, abordagem do conceito e período.

\begin{tabular}{|c|c|c|c|}
\hline Tipo & Artigos & Teses/Dissertações & Cap. de livro \\
\hline $\begin{array}{c}\text { Abordagem do } \\
\text { conceito }\end{array}$ & 101 & 11 & 10 \\
\hline Período & Objeto & Unidade de análise & $\begin{array}{c}\text { Elemento teórico } \\
\text { central }\end{array}$ \\
\hline & $1991-2008$ & 30 & 60 \\
\hline & 5 & $2009-2013$ & $2014-2018$ \\
\hline
\end{tabular}

Estes 122 trabalhos coletados distribuíram-se da seguinte forma, quanto ao tipo de publicação: 101 artigos, 11 teses e dissertações e dez capítulos de livro. É natural que a busca resulte em um número superior de artigos, tendo em vista a pesquisa vinculada a bases de dados de periódicos. Um livro, com diversos capítulos representados neste material, é Perezhivanie, Emotions and Subjectivity: Advancing Vygotsky's Legacy (FLEER; GONZÁLEZ-REY, VERESOV, 2017). Trata-se de produção recente com foco particular no conceito de vivência e em sua relação com o tema das emoções e subjetividade.

Quanto à forma de abordagem do conceito vivência, 60 trabalhos abordaram-no como elemento teórico central, 32 como objeto de discussão e 30 como unidade de análise. O periódico Mind, Culture and Activity, conforme mencionado na introdução, publicou um número especial sobre vivência em 2016 com o objetivo de debruçar-se sobre o conceito, suas diferentes traduções e 
apropriações. Dessa publicação, 15 artigos estão contemplados na categoria "objeto de discussão".

No tocante ao ano de publicação obteve-se trabalhos de 1991 a 2018, os quais foram organizados tendo em vista intervalo de tempo e volume de publicação, de modo a distribuir melhor os resultados obtidos. As divisões foram feitas nos seguintes períodos: 1991 a 2008, cinco publicações acessadas, observando-se um intervalo de cinco anos (2004 a 2008) sem publicações encontradas; 2009 a 2013, 25 publicações; 2014 a 2018, 92 publicações. Embora a amostra representada no presente trabalho não contemple todas as produções sobre vivência, por trabalhar apenas com publicações em inglês, português e espanhol - tendo excluído o francês pela ausência de estudos encontrados sobre o tema -, e tendo em vista ainda limitações de acesso a materiais, além de limitações que podem se impor à própria ferramenta de busca utilizada (por eventualmente não ter acesso a todos os periódicos de determinado contexto), o resultado revela um aumento exponencial das produções sobre o tema no intervalo de tempo pesquisado. Este dado aponta e confirma o interesse crescente de pesquisadores pelo conceito em foco, sobretudo a partir de 2009.

Em relação aos anos de publicação das produções que tratam o conceito de vivência como objeto de discussão, apenas um trabalho foi registrado no período de 1991 a 2008; entre 2009 e 2013 foram 3 trabalhos registrados; e entre 2014 e 2018, 28 trabalhos. Ainda que tenha havido aumento ao longo dos anos, é importante pontuar que o ano de 2016, tendo em vista a publicação do número especial sobre vivência pelo periódico Mind, Culture, and Activity, foi um ano atípico de muita produção nessa direção, contemplando 21 das 28 publicações do período de 2014 a 2018. Esse dado aponta um esforço expressivo recente neste tipo de discussão (teórica, conceitual) do tema, fundamento para a apropriação do conceito e sua utilização, seja como unidade de análise ou elemento teórico central. 
Gráfico 1 - Distribuição da produção por região geográfica.

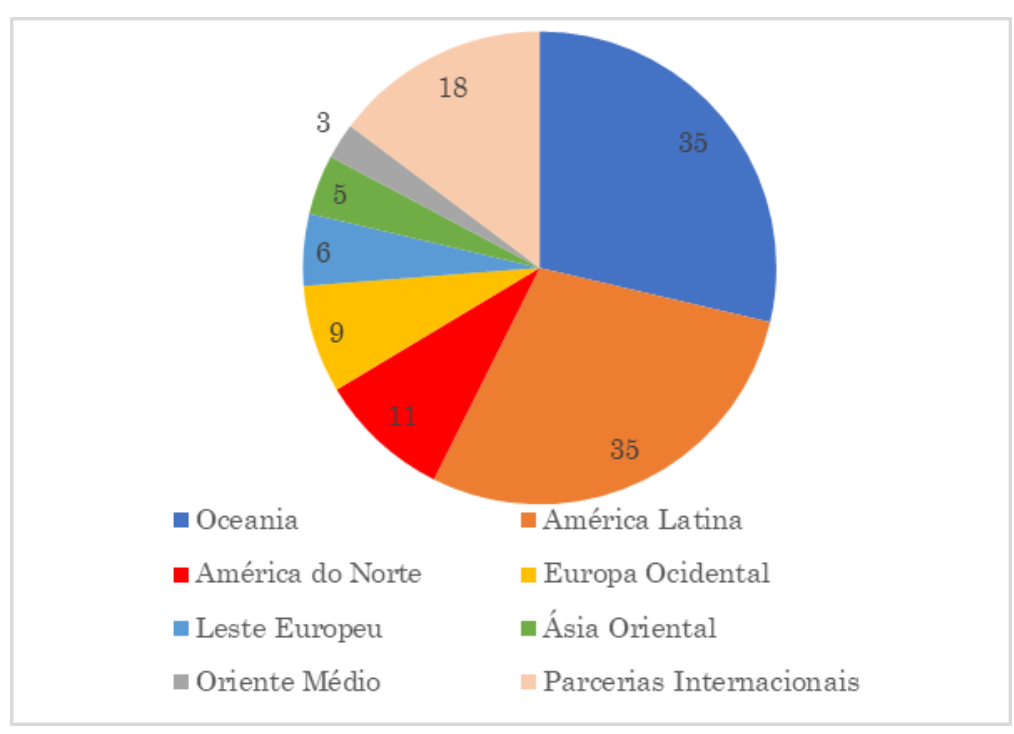

Foram registradas produções oriundas de 22 países diferentes, tendo em vista a universidade de vinculação dos autores, dado que aponta para a disseminação do interesse pelo conceito ao redor do mundo. Esses 22 países foram divididos por regiões geográficas, de modo que a distribuição dos trabalhos resultou no seguinte: América Latina (Brasil, Cuba, Argentina e México) e Oceania (Austrália e Nova Zelândia), 35 trabalhos cada região; América do Norte (Estados Unidos e Canadá), 11 trabalhos; Europa Ocidental (Espanha, Finlândia, Reino Unido, Grécia e Holanda), nove trabalhos; Leste Europeu (Rússia), seis trabalhos; Ásia Oriental (China e Japão), cinco trabalhos; Oriente Médio (Israel e Irã), três trabalhos; Além de 18 produções realizadas em parcerias internacionais. Estas envolveram principalmente América do Norte (Estados Unidos e Canadá), Europa Ocidental (Espanha, Noruega, Suécia, Islândia e Reino Unido), América Latina (Brasil, Cuba e México) e Oceania (Austrália e Nova Zelândia), mas também Ásia Oriental (Vietnam) e Leste Europeu (Rússia). 
Gráfico 2 - Distribuição da produção por países (considerando parcerias).

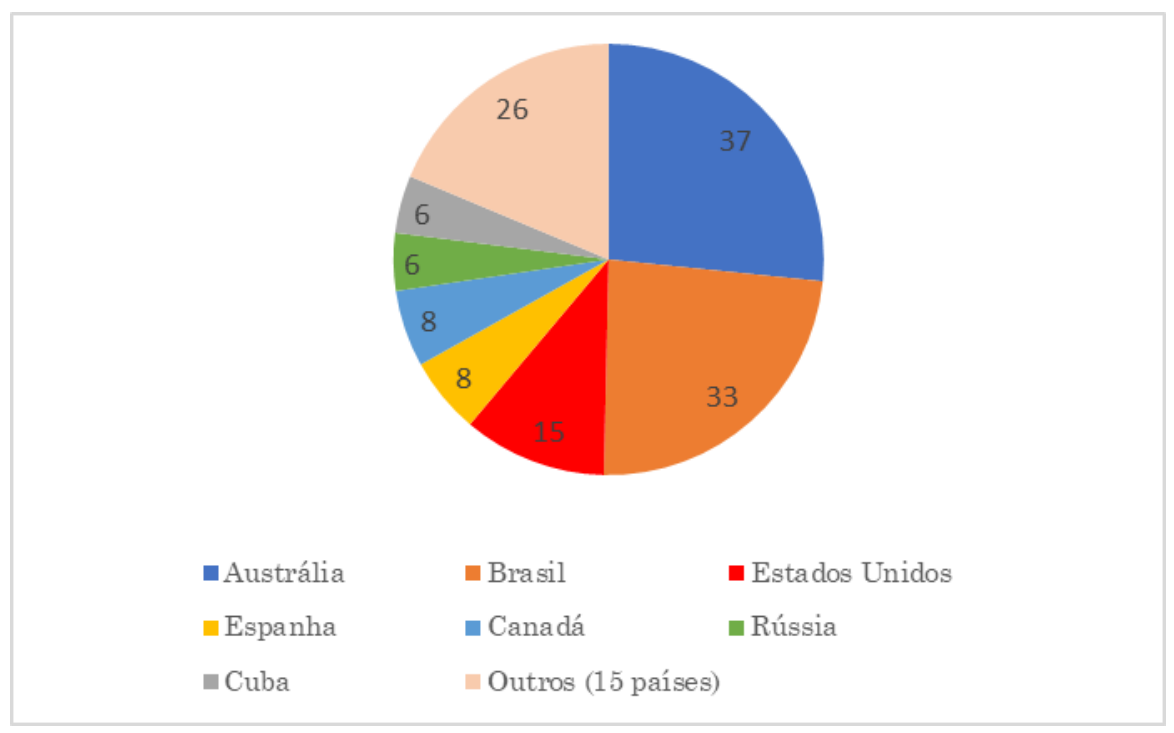

É compreensível que, por limitações relacionadas ao idioma, não se registre, na amostra tratada, um número maior de trabalhos oriundos da Rússia ou de outros países do Leste Europeu, berço de Vigotski. O número menos expressivo de trabalhos produzidos em outras regiões (Europa Ocidental, Ásia Oriental e Oriente Médio) também pode se dever a limitações linguísticas; contudo, diferente da Rússia, não se sabe de tradição robusta na discussão de temas relacionados à perspectiva histórico-cultural nestas regiões, sobretudo na Ásia e Oriente Médio. Da amostra analisada, os países com maior produção, contando as parcerias internacionais, são: Austrália, com 37 trabalhos; Brasil, com 33; Estados Unidos, com 15; Espanha e Canadá, ambos com oito cada um; Rússia e Cuba, cada um com seis. Os demais países tiveram menos de cinco produções representadas na amostra.

O Brasil se destaca, no contexto da América Latina, em relação ao número de produções sobre o tema, seguido de Cuba. Embora possa ter havido limitações em relação à ferramenta de busca na pesquisa por trabalhos em espanhol, ainda que ela cubra as principais bases de dados latino-americanas, a diferença do número de produções brasileiras em comparação ao dos outros países da América Latina é muito expressiva. Além de Brasil e Cuba, somente México e Argentina estão representados. Esta importante presença brasileira de produções envolvendo o conceito de vivência contrasta com os escassos resultados obtidos 
em revisão bibliográfica de 2006, realizada por Toassa e Souza (2010), dado que revela o quanto a produção sobre o tema vem crescendo no país desde então.

Em relação aos autores com mais produções relacionadas ao conceito de vivência identificados na amostra, muitos se destacam no contexto australiano: Nikolai Veresov (nove produções), Marilyn Fleer (dez produções), Nelson Mok (quatro produções), Megan Adams (quatro produções), Glória Quiñones (três produções) e Sue March (duas produções), todos pertencentes à Monash University, que responde por 26 do total de 37 produções australianas registradas. Foram também registradas produções em outras cinco universidades na Austrália, nas quais alguns autores aparecem com mais de um trabalho: Susan Davis (Central Queensland University) e Andy Blunden (University of Melbourne).

No cenário brasileiro destaca-se Fernando González-Rey, falecido em março deste ano, com 11 produções, tendo a Universidade de Brasília e/ou o Centro Universitário de Brasília, ambas instituições de trabalho do pesquisador, representação em 17 das 33 produções brasileiras registradas na amostra. As produções em contexto brasileiro revelaram um cenário heterogêneo, com diversos autores oriundos de diferentes universidades (um total de 15, dentre elas: USP, UFPB, UFG, UFF, UFPI etc.) tratando do tema, o que aponta sua disseminação pelo Brasil. Outros autores contemplados mais de uma vez nos trabalhos registrados são Gisele Toassa (Universidade Federal de Goiás) e Zóia Prestes (Universidade Federal Fluminense).

Nos Estados Unidos o cenário também é diversificado, sendo representadas 11 universidades das 15 produções registradas. Autores com mais de um trabalho presente na amostra são: Beth Ferholt (City University of New York); Luis C. Moll (University of Arizona); Holbrook Mahn (University of New Mexico); Michael Cole (University of California); e Paula R. Golombek (University of Florida).

No Canadá, com suas oito produções registradas, o cenário representado é menos diverso. Dentre elas, seis foram escritas por Wolff-Michael Roth (University of Victoria), das quais cinco são parcerias internacionais, sobretudo com o pesquisador Alfredo Jornet, da Universidade de Oslo (Noruega), que 
comparece em três produções. Da mesma forma, na Espanha o cenário revelado envolve predominantemente dois pesquisadores: Marc Clarà (Universitat de Lleida), com quatro produções, e Moisés Esteban-Guitart (Universitat de Girona), com três produções; somando sete, dos oito trabalhos registrados.

Há poucos elementos para falar dos cenários representados na amostra em relação a outros países, mas autores que apresentaram mais de uma produção no contexto da pesquisa foram O. V. Rubtsova (Moscow State University of Psychology and Education, Rússia); Fariñas León (Universidad de la Habana, Cuba); Adam Poole (University of Nottingham Ningbo China); e Alex Kozulin (Feuerstein Institute e Tel Aviv University, Israel).

Gráfico 3 - Distribuição da produção por periódicos (artigos).
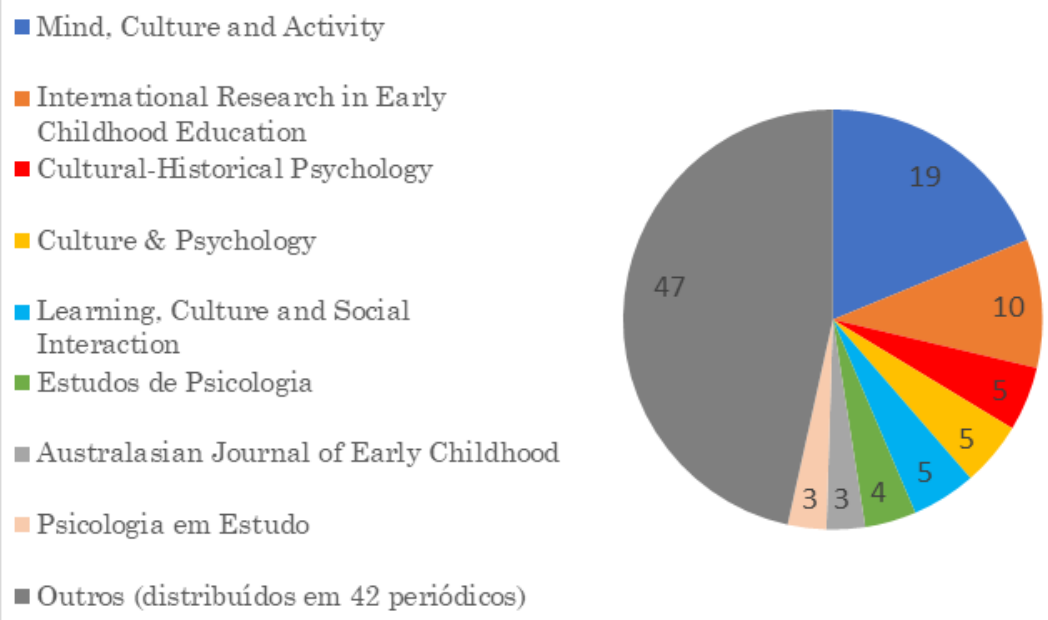

No tocante aos periódicos de publicação dos trabalhos registrados (em se tratando dos artigos) 50 títulos foram contabilizados, dos quais destacam-se o já mencionado Mind, Culture and Activity, com 19 publicações - sendo 15 do dossiê referido sobre vivência; o International Research in Early Childhood Education, da Universidade de Monash, com dez publicações; o Cultural-Historical Psychology, da Moscow State University of Psychology and Education, com cinco publicações; o Culture \& Psychology, editado por Jaan Valsiner (Aalborg University, Dinamarca), com cinco publicações; o Learning, Culture and Social Interaction, editado por Harry Daniels (University of Oxford, Reino Unido), Roger Säljö (University of Gothenburg, Suécia) e Heila Lotz-Sisitka (Rhodes University, 
Africa do Sul), com cinco publicações; e o Australasian Journal of Early Childhood, editado por Lennie Barblett (Edith Cowan University, Austrália), com três publicações. Três dos periódicos mencionados (Mind, Culture and Activity, Cultural-Historical Psychology e Learning, Culture and Social Interaction) estão associados à já referida ISCAR, International Society of Cultural-Historical Activity Research.

No cenário brasileiro destaca-se a revista Estudos de Psicologia, da PUCCampinas, com quatro publicações, e a revista Psicologia em Estudo, da Universidade Estadual de Maringá, com três publicações. Os demais periódicos contam com duas publicações ou menos e não serão citados.

Os periódicos encontrados abrangem, predominantemente, os campos da psicologia, educação e desenvolvimento humano. Dentre os 50 encontrados, 15 (correspondendo a 29 publicações) fazem referência direta à psicologia (compreendendo a palavra "psicologia"), e 19 (correspondendo a 32 publicações) apresentam referência direta à educação (abarcando termos tais "educação" e seus derivados, "ensino" e "aprendizagem"), ambos podendo tratar de assuntos na interface dos campos mencionados. Muitos periódicos que não apresentaram referência direta à psicologia e/ou à educação utilizaram termos específicos que envolvem um e outro campo ("desenvolvimento", "linguagem", "primeira infância”).

Um campo de pesquisa identificado e com presença expressiva, manifestado nos títulos dos periódicos de referência dos artigos, é o do desenvolvimento na primeira infância, com cinco títulos ligados ao tema, correspondendo a 18 publicações. Este dado não é surpreendente, levando em consideração que o conceito de vivência foi elaborado por Vigotski no contexto do estudo do desenvolvimento infantil, embora possa ser utilizado em outros campos. Das 18 publicações referidas, 11 correspondem ao contexto Australiano, das quais nove pertencem à Monash University.

\section{Conclusão}

O presente trabalho traz contribuições relevantes para a análise do panorama nacional e internacional da pesquisa relacionada ao conceito de 
vivência no contexto da teoria histórico-cultural, ainda que aborde um recorte desta realidade. Constata-se significativa produção referente ao tema (representada pelos 122 trabalhos coletados) e seu crescimento exponencial, sobretudo ao longo dos últimos dez anos, apontando o aumento do interesse dos estudos na área. A produção registrada contempla 22 países de sete regiões geográficas diferentes, indicando disseminação a nível internacional das pesquisas envolvendo o conceito. Austrália e Brasil destacam-se neste cenário em número de trabalhos (cada um com mais de 30 registros), seguidos dos Estados Unidos (15 registros).

No contexto Australiano é evidente o protagonismo da Monash University, que reúne diversos pesquisadores (com destaque para Nikolai Veresov e Marilyn Fleer) atuantes nos estudos envolvendo vivência, revelando interesse particular no campo do desenvolvimento na primeira infância. $O$ cenário brasileiro apresenta participação central de Fernando González-Rey, da Universidade de Brasília e do Centro Universitário de Brasília, nas produções encontradas, mas também revela uma realidade diversificada de pesquisadores e universidades produzindo sobre o assunto.

As principais áreas do conhecimento abarcadas pelos estudos, tendo em vista os periódicos de publicação dos artigos, foram educação, psicologia e desenvolvimento humano. Trata-se de campos abrangentes de utilização do conceito de vivência, que podem ser detalhados por uma análise qualitativa dos trabalhos registrados. Nesse sentido, uma primeira leitura já permitiu a identificação de alguns domínios, como: o estudo voltado para o desenvolvimento na primeira infância; o contexto de formação de professores; o contexto de ensinoaprendizagem de língua estrangeira.

A partir do presente estudo consideram-se, ainda, possibilidades de ampliação e aprofundamento da pesquisa. A ampliação seria no sentido de agregar trabalhos aos quais não foi possível o acesso nesse momento e buscar títulos que não tenham sido contemplados, por meio de outras ferramentas de pesquisa e através das referências dos trabalhos registrados. A intenção é estabelecer um panorama mais completo de produções, passível de somar-se a estudos semelhantes de outros países, envolvendo trabalhos em outros idiomas 
que explorem melhor esses distintos contextos. Por sua vez, um aprofundamento envolveria diversas possibilidades e, para isso, a classificação das produções quanto à forma de abordagem do conceito (objeto de discussão, unidade de análise e elemento teórico central) seria particularmente útil.

$\mathrm{O}$ aprofundamento nos textos referentes à vivência como objeto de discussão poderia contribuir para mapear as percepções e apropriações dos autores sobre o conceito, divergências e concordâncias. $\mathrm{O}$ foco nas produções que utilizam vivência como unidade de análise central contribuiria na visualização de caminhos metodológicos de análise, semelhanças e diferenças. O aprofundamento nos trabalhos envolvendo o conceito como unidade de análise e elemento teórico central poderia ajudar, conforme já mencionado, a fazer um levantamento das suas áreas e formas de utilização (se faz referência a algum entendimento específico do conceito, por exemplo), levando em consideração ainda a articulação à perspectiva histórico-cultural de forma mais ampla. Outras possibilidades incluem estudos de recortes específicos, como a produção sobre o tema no Brasil ou na América Latina, grupos que se destacam, modos de entendimento e áreas de utilização do conceito.

Os dados e possibilidades apontadas no presente trabalho são relevantes tendo em vista o crescimento e difusão dos estudos envolvendo o conceito de vivência no Brasil e no mundo (conforme atestam resultados da atual pesquisa), seu potencial de contribuição, além de sinalizar perigos implicados no uso superficial do conceito. Para tanto, só uma análise aprofundada dos materiais poderia contribuir de forma mais efetiva.

\section{Referências}

CLARÀ, M. The many lives of the word perezhivanie. In: COLE, M.; GAJDAMSCHKO, N. (ed.) MCA Symposium on Perezhivanie, p.70-73, 2016. Disponível em: https://www.semanticscholar.org/paper/MCA-Symposium-onPerezhivanie/63888aa89d34d3cf2f3011c546684cc3f38e3bd4. Acesso em: 15 jun. 2018.

COLE, M.; GAJDAMSCHKO, N. The Growing Pervasiveness of Perezhivanie. Mind, Culture, and Activity, vol.23, n.4, p.271, 2016. 
FLEER, M.; GONZÁLEZ-REY, F.; VERESOV, N. (orgs.). Perezhivanie, Emotions and Subjectivity: Advancing Vygotsky's Legacy. Singapura: Springer, 2017.

ROTH, W-M; JOURNET, A. Perezhivanie in the Light of the Later Vygotsky's Spinozist Turn Mind, Culture, and Activity, vol.23, n.4, p.46-55, 2016.

TOASSA, G.; SOUZA, M. P. R. de. As vivências: questões de tradução, sentidos e fontes epistemológicas no legado de Vigotski. Psicologia USP, São Paulo, vol. 21, n.4, p. 757-779, 2010.

VERESOV, N. Emotions, perezhivanie et développement culturel: le projet inachevé de Lev Vygotski. In : MORO, C.; MIRZA, N. M. (Ed.) Sémiotique, culture et développement psychologique. Lausanne: Septentrion, 2014, p.209-237.

VERESOV, N.; FLEER, M. Perezhivanie as a theoretical concept for researching young children's development. In: COLE, M.; GAJDAMSCHKO, N. (Ed.) $M C A$ Symposium on Perezhivanie, p. 56-66, 2016. Disponível em: https://www.semanticscholar.org/paper/MCA-Symposium-on-

Perezhivanie/63888aa89d34d3cf2f3011c546684cc3f38e3bd4. Acesso em: 15 jun. 2018

VIGOTSKI, L.S. Quarta aula. O problema do meio na pedologia. In: PRESTES, z.; TUNES, E. (org.) 7 Aulas de L. S. Vigotski sobre os fundamentos da pedologia. Rio de Janeiro: E-Papers, 1935/2018, p. 73-92. 